\title{
What Do Millennials Desire For? A Study of Expectations From Workplace
}

\author{
${ }^{1}$ Dr. Ruchi Sao, ${ }^{2}$ Prof. Kanchan Tolani \\ ${ }^{1,2}$ Assistant Professor, Shri Ramdeobaba College of Engineering and Management, Nagpur \\ Email:saorn@rknec.edu,tolanik1@rknec.edu
}

Received: $20^{\text {th }}$ September 2018, Accepted: $11^{\text {th }}$ October 2018, Published: $31^{\text {st }}$ October 2018

\begin{abstract}
The study focuses on understanding the expectations of millennials from the organization with respect to performance management, working style, norms and culture. Managing millennials has always been a concern for organizations due to high expectations with respect to flexible working hours, rewards and autonomy at work. They are smart and want to leave their footprint at work. Attracting the millennials for their job is really easy. The difficult part starts when they start working in organization.

The expectations of the millennials are completely different from that of the baby boomers with respect to employment experience. Millennials prefer to work on projects which test their intelligence levels and seek challenges. At the same time, they want to travel, explore the world and maintain a good work life balance.

Data was collected in the form of checklist of general expectations that millennials have from the organization. Data is captured from 80 post graduate management students who would be entering the workforce as millennials. Eighteen parameters were identified and the millennials ranked their preferences from the expectations. The top five expectations identified in the study are good salary and perks, job security, five day working, work life balance \& recognition and appreciation and challenging roles in job \& allowed to be innovative.

This study will help the organizations to understand the mindset of the new generation coming to work so that their potential can be best utilized. It will also help the organizations to create a workplace environment which best suits the millennials.
\end{abstract}

\section{Keywords}

Millennial Expectations, Multi-Generational Workforce, Work Environment

\section{Introduction}

The millennial generation are the employees who are born between the year 1981 and 2000 and are still the youngest generation to enter the workforce. They are the one who have high energy, are ready to go beyond the job, have broader perspectives, are confident and want to grow and be successful. The millennials are quite flexible provided their work is acknowledged and appreciated. While the millennials entered the workforce, they got an opportunity to work with both baby boomers and generation X. the rise of college students seeking employment at a young age has seen a drastic growth in the past years. The millennial generations are the one who have high expectations from the organizations with respect to salary, work culture and environment. It is difficult for the corporates to attract and retain the millennials in the workforce. This study explores the expectations of the millennials from the workplace. The job description and cost to company are tailor made during campus interviews and job fairs in order to attract the millennials. The companies today are investing a huge amount of money in infrastructure, indirect benefits and the welfare of the employees.

In a study undertaken on sales workforce by Dr. Roberta J. Schultz (2012) it was found that with respect to key sales management issues, there are differences in the expectations of Boomers and Millennials. Boomers seem to like team concept and they believe that the achievements of team and individuals should be jointly acknowledged. While millennials prefer individual recognition over team recognition.

The millennials are ready to work in team but always expect rewards and recognition in terms of individual levels. A similar study (Alsop, 2008; Gursoy et al., 2008) revealed that millennials though may prefer individual recognition over team recognition but millennials like working in teams, they find working in groups more interesting. Many researches support the fact that as compared to other generations, millennials have high social needs and have inclination towards working in groups. (Jones, 2010). They focus a lot on the social characteristics of workplace. They like to have friends at workplace and desire to have a working environment which is interesting and engaging. (Ng et al., 2010). A study conducted by (Andrea Hershatter, 2010) suggest that millennials prefer to work in such organizations that have care and concern for its employees. They like to receive continuous feedback at work and want high level of clarity regarding work responsibilities and procedures. The study also found that millennials prefer to work in organizations which help them to achieve work-life balance. 
Various studies reveal that millennials not only have different expectations form work system but they also tend to have different expectation from their leader. A study conducted by Shih Yung Chou (2012). Millennials like frequent communications at workplace. They want their leaders to give regular feedbacks and prefer a participative leadership style wherein information is shared readily and suggestions of everyone are taken for all the issues. Another study revealed that a leadership style that can boosts relationships and meet individual requirements is more likely to attract Millennials. (Avolio \& Bass, 1995).

Few researches on millennials found that millennial expectations from work about job content, career growth, benefits and salary are high as compared to other generations. These expectations are highly influenced by an individual's personal variables such as positivity, career orientation etc. (Sara De Hauw et al, 2010)

A similar study conducted on Nurse Graduates suggested that millennials expect that at workplace they should be valued and treated professionally. They like to have a supportive work environment and collaborative approach to goal achievement. (Diane Randall Andrews, 2013). Millennials give a lot of emphasis to the work content, they like to quickly upgrade their skills and like a job that provides them work satisfaction. (Eddy S.W. Ng, 2010)

In an attempt to find out if millennials like to work in a socially responsible organization, several studies discovered that millennial are more attracted to work in an organization if the organization is known for its CSR activities and advertisements that reveal more information about the company's CSR attract more millennial applicants. (Victor M. Catano et al., 2015)

In the coming years, the millennials are the one who will continue to joint eh workforce at entry level and middle level management for the coming five years. It is important that the HR department starts getting geared up to welcome the millennials and embrace their expectations for high performing teams.

\section{Material and Methods}

For the current study, primary data was collected through questionnaire which was circulated to 100 post graduate management students. The sampling technique used was convenience sampling. Out of which, 80 responses were captured. Parameters of the questionnaire were identified on the basis of focus group discussions (FGD) and literature review. Extensive literature review was done to identify the expectations of the millennials. The parameters identified are allowed to be innovative, work life balance, five day working, care from organization, brand of organization, freedom to choose assignments, flexibility at work, fun at work, good salary and perks, challenging roles in job, interesting job, support from leader, ethical organization, career advancement, encourage to pursue hobbies and passion, motivates entrepreneurship, recognition and appreciation and job security.

The respondents ranked the parameters based on their expectations from workplace. The paper would report the rankings and identify the top five expectations.

The objectives of the study are as under:

- To identify the workplace expectations of millennials

- To identify the top five expectations of millennials

- To suggest ways to retain the millennials

The literature review that has been reported in the introduction part identifies the working patterns and expectations of the millennials from the workforce. The result and discussion part will discuss the ranking and preferences of the millennial generation from the workplace.

\section{Results and Discussion}

The data collected through questionnaire was analyzed in order to understand the preferences of the respondents in terms of their expectations from workplace. The respondents were asked to rank their expectations from workplace from highest to lowest. The top five expectations of millennials are ranked as per the following sequence and explained as under.

\section{Good Salary and Perks:}

As the employee age advances at work, need for intrinsic rewards grows. At the start of the career, the millennials give more importance to extrinsic reward and various types of perks.

Today, the mantra of millennials generation is "Live life king size". To fulfill their needs, they are not ready to wait like the earlier generations and thus they aspire a lucrative package. They believe in creating reserves and at the same time enjoying their life.

Thus, good salary, incentives and perks become the first preference of the millennial generation from their jobs. 


\section{Job Security:}

Majority of the millennials have grown up seeing the changes in economic conditions in India which were discussed by their working parents and elders at home. The early millennials have also witnessed and gone through the phase of recession in the year 2008. Uncertainty in jobs resulted in high pressure, stress and frustration which was carried to home thereby disturbing the family time. Fear of loss of job results in employee spending more energy and time at work resulting in imbalance between work and life. High and consistent performance is required by the employees to maintain their position in the organization.

This background of high uncertainty has led to millennials wanting a stable and secured job and have given second rank to it.

\section{Five Day Working:}

The millennials are ready to work for hours together for the entire week. But, they want their own me time and social time. Along with their jobs, they also wish to pursue their hobbies, live their passion, travel, party hard and fulfill their aspirations. There are many organizations who have taken initiative for four day working also. The concept of dual careers, further studies, involvement in social activities, marathons, etc. have led to the need of four or five day working.

Thus, this makes five day working as the third priority of millennials at work.

\section{Work Life Balance \& Recognition and Appreciation:}

There are two preferences that the millennials have given on the fourth rank which are work life balance and recognition and appreciation.

Employees invest their time and energy into work in order to earn and live a good life. However, in case of excessive working hours and work pressures, it may not be possible to strike the right balance. Work life balance is the key to achievement and enjoyment in life and this is what the employees want at work. The millennials need flexibility at work and autonomy which helps them in achieving the right work life balance by working in a stress free environment.

Extrinsic rewards is of course at the first rank in expectations. Millennials also want appreciation and recognition at work from their seniors. They look for projects and opportunities so as to shown their performance and achieve. Though recognition at the early stage of career is not that important, but surely hold value for the millennials.

\section{Challenging Roles in Job \& Allowed to be Innovative:}

There are two preferences that the millennials have given on the fifth rank which are challenging roles and scope for innovation at job. The millennials have their own style of working which may not match the generation of baby boomers which are in majority in organizations today. They want to enjoy their work by getting the liberty to complete the task according to their own process and speed. Cakewalk kind of tasks do not excite the millennials anymore. They seek for broader jobs and challenges at workplace. The millennials are tech savvy and are really fast at completing their tasks with more accuracy. In fact, this generation also acts as a mentor in the system of reverse mentoring these days.

Thus, all these expectations form the top five amongst all. Some also reported that they want good relationship with the leaders. The study also identifies the least expected preferences of the millennials from the workplace out of the 18 parameters. In the order of 16 to 18 , following are the least expected of from the workplace.

- Motivates entrepreneurship

- Organization encourage to pursue hobbies and passion

- Freedom to choose assignments

\section{Conclusion}

The paper identifies the top five ranked expectations from the workplace of the millennials which are; good salary and perks, job security, five day working, work life balance \& recognition and appreciation and challenging roles in job \& allowed to be innovative.

The millennials are the youngest generation in the workforce and in the coming years will have the longest job tenure. They are the one who will occupy the higher leadership role in a couple of years. It is the need of the hour that the corporate sector understands the expectations of the millennials in order to be future ready.

The current research focuses on understanding the expectations of Millennials from job and the study is undertaken on Management students studying in a college of Nagpur hence the findings of this study cannot be generalized. So similar study can be done in other colleges of other cities, states and countries. In depth study of the expectations identified in this study can be conducted to determine various strategies which can be adopted by organizations to 
retain and maintain millennials. Further research can be undertaken for understanding the role of Gender and other demographically factors impacting millennial expectations. Also studies can be carried out to find out the challenges faced by millennials at work.

\section{References}

1. Schultz, R.J., Schwepker, C.H., Davidson, M. and Davidson, P., 2012. Boomers vs. Millennials: Critical conflict regarding sales culture, salesforce recognition, and supervisor expectations. International Journal of Business, Humanities and Technology, 2(1), pp.32-41.

2. Chou, S.Y., 2012. Millennials in the workplace: A conceptual analysis of millennials' leadership and followership styles. International Journal of Human Resource Studies, 2(2), pp.71-83.

3. Myers, K.K. and Sadaghiani, K., 2010. Millennials in the workplace: A communication perspective on millennials' organizational relationships and performance. Journal of Business and Psychology, 25(2), pp.225238.

4. Jones, C., Ramanau, R., Cross, S. and Healing, G., 2010. Net generation or Digital Natives: Is there a distinct new generation entering university?. Computers \& education, 54(3), pp.722-732.

5. Ng, E.S., Schweitzer, L. and Lyons, S.T., 2010. New generation, great expectations: A field study of the millennial generation. Journal of Business and Psychology, 25(2), pp.281-292.

6. De Hauw, S. and De Vos, A., 2010. Millennials' career perspective and psychological contract expectations: does the recession lead to lowered expectations? Journal of business and psychology, 25(2), pp.293-302.

7. Andrews, D.R., 2013. Expectations of millennial nurse graduates transitioning into practice. Nursing administration quarterly, 37(2), pp.152-159.

8. Catano, V.M. and Morrow Hines, H., 2016. The influence of corporate social responsibility, psychologically healthy workplaces, and individual values in attracting millennial job applicants. Canadian Journal of Behavioural Science/Revue canadienne des sciences du comportement, 48(2), p.142.

9. Hershatter, A. and Epstein, M., 2010. Millennials and the world of work: An organization and management perspective. Journal of Business and Psychology, 25(2), pp.211-223.

10. Avolio, B.J. and Bass, B.M., 1995. Individual consideration viewed at multiple levels of analysis: A multi-level framework for examining the diffusion of transformational leadership. The leadership quarterly, 6(2), pp.199218.

11. Ng, E.S., Schweitzer, L. and Lyons, S.T., 2010. New generation, great expectations: A field study of the millennial generation. Journal of Business and Psychology, 25(2), pp.281-292. 